\title{
Negras in tech: apropriação de tecnologias por mulheres negras como estratégias de resistência*
}

\author{
Dulcilei C. Lima** \\ Taís Oliveira***
}

\section{Resumo}

Em 2018, a iniciativa PretaLab publicou o resultado de um levantamento que mapeou a inserção de mulheres negras $e$ indígenas nas TICs. Este artigo analisa esses dados em busca de compreender a apropriação de tecnologias por mulheres negras como estratégias de resistência. Foram analisados os dados estatísticos e depoimentos em vídeo, além de 15 projetos mencionados pelas entrevistadas onde se aplicou a Análise de Redes Sociais na Internet (ARS). Vimos que as mulheres negras buscam dominar as tecnologias, a fim de propor soluções para as brechas tecnológicas e fazer uso social das habilidades adquiridas.

Palavras-chave: Mulheres Negras, Tecnologia, Estratégias de Resistência, TIC.

* Recebido em 27 de setembro de 2019, aceito em 11 de agosto de 2020.

** Doutora em Ciências Humanas e Sociais pela Universidade Federal do ABC (UFABC). Integra o NEAB - UFABC. Pesquisadora do Centro de Pesquisa e Formação do SESC - SP, São Paulo, SP, Brasil. dulcilima78@gmail.com / https://orcid.org/0000-0002-5136-3341.

*** Mestre e doutoranda no Programa de Pós-Graduação em Ciências Humanas e Sociais na Universidade Federal do $\mathrm{ABC}$ (UFABC), linha de pesquisa em Políticas Públicas, participação social e ação coletiva, São Paulo, SP, Brasil. Integra o NEAB - UFABC. taisso@gmail.com / https://orcid.org/0000-0003-10642755 
Black Women in Tech: Appropriation of Technologies as Resistance Strategies

\begin{abstract}
In 2018, the PretaLab initiative published the result of a survey that mapped the inclusion of black and indigenous women in ICTs. The article analyzes the data generated by the survey to understand the appropriation of technologies by black women as resistance strategies. Statistical data and video testimonies were analyzed, in addition to 15 projects identified by the interviews, which conducted an Analysis of Social Networks on the Internet. We can see that black women seek to gain command of technologies to propose solutions to technological gaps and make social use of acquired skills.
\end{abstract}

Keywords: Black Women, Technology, Resistance Strategies, ICT. 


\section{Introdução}

Falar de mulheres negras nas tecnologias requer abordar, ainda que brevemente, o não-lugar que ocupam na cadeia tecnológica. Brecha tecnológica ou o que Canclini (2015) também chama de techno-apartheid se configura na reprodução das desigualdades sociais no universo tecnológico. Grupos subalternizados, com pouco ou nenhum acesso à educação, acometidos por deficiências socioeconômicas e pertencentes a grupos minoritários como mulheres, negros e indígenas, enfrentam dificuldades de acesso e uso das ferramentas tecnológicas. Pesam ainda sobre esses grupos, a "discriminação linguística, [...] marginalização territorial $e$ [...] subestimação de saberes tradicionais ou sua baixa legitimidade jurídica" (Canclini, 2015:234).

Os estudos feministas apontam há décadas que o campo da tecnologia reproduz as desigualdades de gênero observadas no cotidiano social associando os homens ao desenvolvimento de tecnologias e às carreiras tecnológicas e frequentemente ocultando as mulheres que fizeram parte de sua história (Conley, 2017; Hearn; Husu, 2011; Wajcman, 2000). Wajcman (2000) ressalta o impacto da exclusão de alguns grupos nos processos de desenvolvimento tecnológico, no entanto, sua crítica se restringe à ausência de mulheres na produção tecnológica sem considerar as distintas realidades femininas inerentes a grupos racializados e/ou empobrecidos. Sandra Harding (2003), por sua vez, atenta às desigualdades sociais associadas às questões de gênero alerta que

[...] quando relações de gênero são renegociadas, outras formas significativas de relações sociais sempre estarão presentes, tais como de classe, raça, sexualidade e poder. Conseqüentemente, as perspectivas de gênero sobre a mudança científica ou tecnológica sempre terá implicações nessas outras áreas da luta social (Harding, 2003: s.p.).

A desigualdade social informa não só pelas impossibilidades quanto à apropriação das tecnologias, mas também incide na 
forma como são apropriadas, com frequência "através de formas e práticas diferenciadas" (Santos, 2018:106). Os sujeitos socialmente excluídos incorporam as tecnologias pelos mais distintos motivos e fazem uso criativo desses recursos em seu cotidiano, renegociando seus significados e usos (Wajcman, 2000) como demonstrado na pesquisa Domésticas conectadas realizada pelo Internet Lab e Rede Conhecimento Social $(2018)^{1}$. Entre os vários resultados dessa pesquisa, constatou-se que tais mulheres acessam a internet em média há apenas seis anos e $98 \%$ delas o fazem somente através do celular. O celular é utilizado como passatempo no trajeto entre a residência e o trabalho e como "forma de continuar administrando a vida doméstica" à distância como acompanhar a rotina dos filhos (InternetLab; Rede Conhecimento Social, 2018:45).

Quanto a brecha tecnológica de gênero, pode ser definida pela limitação de acesso, uso e apropriação das TICs (Tecnologias da Informação e Comunicação) pelas mulheres. Collado (2008) a caracteriza em três divisões: o acesso a equipamentos tecnológicos e internet; o uso das ferramentas digitais e internet; e a produção das tecnologias.

A autora aponta que as desigualdades entre homens $e$ mulheres no acesso, uso e criação de tecnologias é grande tanto em países desenvolvidos quanto em países em desenvolvimento. Ainda que o acesso seja a divisão que apresenta menor distância entre os gêneros, não é um dado desprezível, considerando que segundo Collado (2008) a principal questão nesse caso se refere à

1 A pesquisa desenvolvida pela InternetLab em parceria com a Rede Conhecimento Social teve como propósito produzir dados sobre o "papel das tecnologias digitais na vida de mulheres trabalhadoras domésticas" (INTERNETLAB; REDE CONHECIMENTO SOCIAL, 2018: 2). O recorte nesse grupo de profissionais se deu pelo interesse em gerar dados sobre o uso de tecnologias pela população de baixa renda e entre trabalhadores domésticos, as mulheres representam cerca de $96,2 \%$ do total, conforme o DIEESE (2017). Na etapa quantitativa, 400 trabalhadoras domésticas foram entrevistadas, $66 \%$ delas se auto identificaram como Pretas ou Pardas. Outras 27 trabalhadoras domésticas compuseram um grupo de reflexão que auxiliou no desenvolvimento do questionário utilizado na quantitativa e na análise dos dados gerados pelas entrevistas. 
qualidade de acesso: "a disponibilidade técnica e a qualidade do acesso são condição necessária, ainda que não suficiente, para o acesso. $\mathrm{O}$ acesso à Internet é um fenômeno social $e$ as condições sociais do acesso são importantes" (Collado, 2008:s.p.). A autora argumenta que grande parte das mulheres que têm acesso à internet não o fazem por meio do computador, mas apenas dos smartphones, a exemplo dos dados obtidos pela pesquisa Domésticas conectadas, e estes possuem recursos mais limitados se comparados aos computadores.

A qualidade do acesso está intimamente relacionada com a segunda brecha digital de gênero ${ }^{2}$, o uso qualitativo das ferramentas ou o que a autora chama de digital literacy, ou seja, o letramento ou alfabetização digital, que se pode definir como o conjunto de habilidades técnicas e cognitivas necessárias para manipular as TICs. O uso da internet, por exemplo, requer certos conhecimentos para busca das informações, avaliação, processamento, apresentação e utilização para o alcance dos objetivos almejados (Collado, 2008). Sem dúvidas, é possível fazer uso da internet sem conhecimentos aprofundados sobre software ou hardware, mas para que o uso não se restrinja ao consumo passivo de informações, mas que possibilite também a criação de conteúdo, é fundamental ter algum conhecimento sobre manipulação das ferramentas digitais, razão pela qual Collado (2008) afirma que a segunda brecha digital de gênero é uma brecha de conhecimento. $\mathrm{O}$ déficit de conhecimento tecnológico, mesmo quando há formação superior, cria obstáculos para as mulheres no mercado de trabalho, na inserção, manutenção $e$ ascensão na carreira, bem como na obtenção de melhores salários (Collado, 2008). Essa brecha de conhecimento é multifatorial, incide sobre ela não só as questões de gênero, mas também de classe, raça etc.

\footnotetext{
${ }^{2}$ Aqui utilizamos a forma empregada pela autora que opta pela expressão brecha digital de gênero.
} 
[...] tem essa falta de conhecimento tem essa falta de aproximação. Mas a falta de conhecimento não é culpa das pessoas, a falta de conhecimento é culpa de um modelo elitizado de tecnologia que não comporta nossa sociedade (Entrevista de Fernanda Monteiro Lira para o PretaLab).

Collado (2008) credita aos estereótipos de gênero a ausência de mais mulheres na ciência e tecnologia. A autora afirma que mesmo em ambientes economicamente favoráveis, as mulheres não costumam ser incentivadas a seguir carreiras tecnológicas devido ao entendimento equivocado de que o campo é masculino, e que às meninas falta habilidade natural para as ciências e tecnologia. Na família e na escola, as mulheres ainda são educadas para o cuidado, de modo que, com frequência se empenham em carreiras cujo foco é o "cuidar do outro" como as áreas de educação e saúde. De acordo com a autora, isso se reflete também nos usos que homens e mulheres fazem da internet, enquanto eles utilizam com mais frequência para o trabalho e lazer, elas fazem uso mais frequente para solucionar problemas de ordem doméstica.

Graciela Natansohn (2015) considera se tratar da brecha de mais fácil comprovação pela clara ausência ou insuficiência de mulheres em cursos tecnológicos e o "teto de vidro" nas empresas do ramo que impossibilita mulheres de ocupar cargos estratégicos nessas corporações.

[...] as teorias feministas entendem a divisão digital como mais um das manifestações algo estrutural e estruturante: o duplo movimento de expulsão das mulheres do campo da ciência e da tecnologia, o que lhes impede de participar dos processos de construção e legitimação de conhecimento, ao mesmo tempo em que se elimina qualquer traço considerado feminino de tal construção (Maffía, 2007). Se a tecnologia é neutra, objetiva e imparcial, assexuada, os "problemas" para se incorporar a ela estariam nas próprias mulheres, na sua cultura, educação e valores, cheios de subjetividade, emoções e irracionalidade. $\mathrm{O}$ que os 
feminismos vêm questionar é o próprio funcionamento do sistema tecnológico e científico, a construção do campo sociotécnico a partir de uma perspectiva que não só exclui as mulheres como todos os grupos que estão fora das formas androcêntricas dominantes, suas formas de conhecimento, experiências, valores e ideologias, isto é, os já discriminados por raça, nacionalidade, cor da pele, classe social, etnia (Natansohn, 2015:258).

Uma das barreiras enfrentadas pelas mulheres é a naturalização da crença de que mulheres são tecnofóbicas. Natansohn (2015:260) defende que não basta garantir às mulheres o uso das ferramentas, é fundamental "incluí-las nas criações tecnológicas, na criação de códigos e softwares, nas decisões macro e micropolíticas". A ampliação de mulheres na criação das TICs, especialmente mulheres conscientes das desigualdades de gênero, pode ser benéfica para sanar problemas em áreas que hoje ocupam grande parte das preocupações feministas no universo digital, como por exemplo, as múltiplas formas de violência contra mulheres na Internet como o ciberassédio, revenge porn, invasão de privacidade e outras. Para Natansohn (2015:261), a "igualdade de gênero em TIC significa usar, mas também programar, manipular, inventar com a tecnologia de maneira proativa". Certas da relevância de ocupar os espaços de criação tecnológica, mulheres feministas que acessaram esses conhecimentos os estão multiplicando em iniciativas como o Minas Programam, MariaLab - Coletiva Hacker Feminista, PrograMaria, Pretas Hackers, OxenTI Menina, PretaLab e outras.

Este artigo se debruça sobre o levantamento realizado por uma dessas iniciativas, o PretaLab - um dos projetos do Olabi, uma organização social que realiza ações para democratização das tecnologias e que é Coordenado por Silvana Bahia. Produzir dados sobre a inserção das mulheres negras $e$ indígenas nas tecnologias é uma das formas de agir ou qualificar a ação junto a essas mulheres, portanto pretendemos analisar os dados do PretaLab Report (bem como as entrevistas em vídeo) publicado em 2018 sob a direção de Silvana Bahia, Gabriela Agustini e Iana 
Baremboim, cujo objetivo do documento foi o de identificar o maior número possível de mulheres negras e indígenas atuantes nas tecnologias e a partir daí compreender quais as necessidades destas no ecossistema da inovação e da tecnologia. Assim, é a partir deste documento e da Análise de Redes Sociais que buscamos responder neste artigo a seguinte pergunta "De que forma as mulheres negras brasileiras têm se apropriado de ferramentas tecnológicas como estratégias de resistência?”.

\section{O acesso à internet pela população negra e de baixa renda}

No que diz respeito ao cenário brasileiro, de um modo geral, a expansão do acesso da população de baixa renda à internet teria se dado a partir de meados dos anos 2000, período de relativo aquecimento econômico quando o poder de consumo foi ampliado, assim como o acesso ao crédito pelos setores mais pobres. Mesmo período em que ocorreu a ampliação $e$ diversificação da conectividade comercial $e$ a popularização do Orkut no Brasil. É também nessa fase que foram criados programas públicos de inclusão digital como o Programa Computador para Todos e a instalação de "Telecentros públicos e comunitários, em locais sem acesso, por meio de organizações sociais conveniadas" (Rosa, 2013). Com essas possibilidades em mãos, muitas famílias adquiriram seus próprios computadores, substituindo aos poucos o uso das Lan Houses, e encontraram formas alternativas de conexão como a banda larga transmitida por sinais de rádio. $\mathrm{O}$ barateamento dos smartphones combinado com a popularização de ferramentas como o Facebook e o WhatsApp, oferecidos gratuitamente nos planos de dados das operadoras, ampliaram consideravelmente o acesso das camadas mais pobres da população à internet (Spyer, 2017).

Infelizmente ainda não existem dados precisos sobre o acesso da população negra às tecnologias $e$ às ferramentas fornecidas pela internet, tampouco sobre seus hábitos de uso. Pesquisas como a PNAD - Acesso à Internet e à Televisão e Posse de Telefone Móvel Celular para Uso Pessoal ou a TIC domicilios, 
por exemplo, não fazem recorte de raça. Sobre exclusão digital a pesquisa Síntese de indicadores Sociais: uma análise das condiçóes de vida da população brasileira (SIS) de 2016, produzida pelo IBGE, revela que $60,8 \%$ da população classificada como preta e parda não tinha acesso à internet em seu domicílio no ano de 2013. A SIS publicada em $2017 \mathrm{fez}$ a divisão por sexo $e$ raça onde se constatou que $37,3 \%$ das mulheres pretas e pardas e $39,1 \%$ dos homens pretos e pardos não tinham acesso à internet contra $24,5 \%$ das mulheres brancas e $24,7 \%$ dos homens brancos. A SIS de 2018 apresentou recuo nesses índices tanto entre brancos quanto entre negros. Nessa última aferição $29,3 \%$ das mulheres pretas e pardas e $30,9 \%$ de homens pretos e pardos não tinham acesso à internet contra $19 \%$ de mulheres brancas e $19,1 \%$ de homens brancos. No que diz respeito às mulheres negras, o Dossiê Mulheres Negras: retrato das condiçóes de vida das mulheres negras no Brasil (2013) do IPEA avaliou a exclusão digital desse segmento populacional a partir da posse de computadores em domicílio e do acesso à internet, e concluiu que os domicílios chefiados por mulheres negras são os que mais carecem desses recursos em comparação com domicílios chefiados por homens negros, mulheres brancas e homens brancos. Esses dados vão de encontro às informações fornecidas pela Síntese de Indicadores Sociais de 2018 do IBGE na sessão que discute restrições de acesso em múltiplas dimensões, que apontam os domicilios chefiados por mulheres negras como os que apresentam maiores restrições de acesso à moradia adequada, educação, proteção social, serviços de saneamento básico e comunicação.

A exclusão da população negra é sentida também no campo de estudos de gênero, ciências e tecnologias como revelado por Costa e Lima (2016). Conforme as autoras, essa área de conhecimento é caracterizada por pesquisadores predominantemente brancos, as lacunas também se apresentam nos recortes de pesquisa que raramente se debruçam sobre a intersecção entre raça, gênero e tecnologia.

Ao analisar a apropriação de tecnologias por mulheres negras brasileiras, Santos (2018) afirma que a despeito 
[...] deste contexto onde se observam marcadas distâncias sócio-econômicas e educacionais, as mulheres negras têm recorrido a esta ferramenta, internet, para expandir seus discursos e criar redes sociais, de maneira que se tem incluído em um contexto também adverso, e não obstante necessário. As mulheres negras vivem em um mundo real em que seus discursos são refutados pelos grandes meios de comunicação, e paralelamente em um mundo digital em que, ao mesmo tempo que se reproduzem valores de exclusão e estereótipos, se facilita às mulheres negras um alcance discursivo incalculável ${ }^{3}$ (Santos, 2018:125).

Neuman (2008) defende a apropriação das tecnologias por parte de grupos socialmente excluídos como potencial exercício de práticas de resistência e negociação frente ao processo de globalização. Percepção compartilhada pela ativista Fernanda Monteiro Lira em entrevista para PretaLab:

Quando você chega nessa percepção em que a tecnologia pode ser um veículo social, você cria outras camadas de resistência, de resiliência, onde você pode se comunicar com outras pessoas que sentem o mesmo que você $e$ isso cria uma sensação de pertencimento que você não tinha antes e leva para lugares inclusive que não tem tecnologia. Pode levar a gente a conhecer não só aquela cultura que tá distante lá no outro país, mas a própria realidade que está do nosso lado.

Silvana Bahia, diretora de projetos do Olabi e coordenadora do PretaLab aborda a relevância da questão tecnológica para a população negra, especialmente mulheres.

[...] as tecnologias estão carregadas com as visões políticas, econômicas $e$ culturais de quem as cria $-e$ esse poder hoje está centrado nas mãos de homens, brancos, heterossexuais, classe média/ricos. Isso já potencializa uma

${ }^{3}$ Tradução nossa. 
grande desigualdade, em um mundo cada vez mais digital. Se as mulheres negras não estiverem nesse processo, se não existirem ações para que elas estejam nesse processo, vamos perder totalmente nosso poder de integração no mundo ${ }^{4}$.

Há uma ambiguidade na ampliação do acesso que não pode ser ignorada, se por um lado, conforme Santos e Pereira (2016) a internet como ferramenta para o ativismo pode possibilitar aos atores sociais "a criação de novos canais de informação e circulação de informações", colaborar na "construção identitária", mobilização e "transformação organizacional" por outro se multiplicam estudos acadêmicos, matérias jornalísticas e denúncias de organizações de direitos humanos que apontam o crescimento da violência digital contra grupos identitários ${ }^{5}$, disseminação do ódio, hipervigilância e manipulação em níveis inéditos, como a disseminação de Fake News, estratégias amplamente utilizadas nas eleições de 2018 e que favoreceram a ampliação dos quadros da extrema-direita no legislativo e no executivo (Braga, 2018; Noble, 2018; Piccinin et al, 2019; Stein et al, 2018).

\section{Identidades nos estudos de tecnologias}

Como em outros setores da sociedade, a indústria tecnológica também é dominada por determinados grupos sociais hegemônicos. Além disso, observa-se também que grandes corporações possuem o poder de controlar a infraestrutura e os fluxos de informação (Silveira, 2008). Deste modo, é de urgente importância a apropriação das ferramentas tecnológicas para a

\footnotetext{
${ }^{4}$ Trecho extraído do vídeo Silvana Bahia - Levantamento PretaLab. Wajcman (2000: 454) utiliza argumento semelhante ao discutir a ausência de mulheres na produção tecnológica ao considerar que como "atividade altamente valorizada $e$ mitologizada" estar no comando da tecnologia equivale a estar "envolvido na direção do futuro".

${ }^{5}$ Ver Relatório "Violências contra mulher na internet: diagnóstico, soluções e desafios" organizado por Coding Rights e InternetLab (2017).
} 
promoção de discussões, problematização e capacitações técnicas de grupos não-hegemônicos. De acordo com Silveira (2008), o "usuário comum" tem a capacidade de se tornar propagador de suas próprias mensagens, criar conteúdo e soluções relacionadas às suas questões sem a mediação de editores.

A partir desses aspectos é possível afirmar que as TICs proporcionam novos fenômenos de estudo e abordagem, sobretudo quando se trata da transversalidade, descentralização $e$ da interatividade que potencializam vozes $e$ visões de mundo diferenciadas Logo, as tecnologias também produzem sentido em seres socialmente situados e esses fazem de seu uso um espaço para manifestações políticas, comerciais, de propagação de opiniões, de associações e formação de comunidades por interesse (Hine, 2015; Lemos, 2015).

A apropriação de plataformas de sociabilidade promove, entre outras possibilidades, a formação de redes sociais na internet que incentivam a interação discursiva $e$ formação de comunidade entre pessoas que se encontram por proximidade de identificação. Logo, compartilhar conteúdos que dão ênfase às características raciais dão aos usuários um sentimento de pertencimento, sobretudo quando estamos tratando de um grupo historicamente estigmatizado e oprimido pela sociedade dominante (Daniels, 2013). Como pode ser observado no seguinte excerto da entrevista de Vitória Lourenço para a PretaLab: "Entende (sic) a tecnologia como um intermediário. E esse intermediário me ajudou a me soltar mesmo. Isso permitiu, por exemplo, que eu me identificasse muito mais como mulher negra. $\mathrm{E}$ isso só aconteceu através da tecnologia".

Munanga (1999; 2012) ao falar da identidade dos movimentos negros contemporâneos, afirma que esses grupos buscam reforçar sua cultura ancestral, fortalece os laços de solidariedade entre o grupo e ressalta aspectos políticos baseados nas exclusões sociais decorrentes do racismo. Bem como afirma Gomes (2005), a identidade negra se constrói com a intersecção de múltiplas variáveis sociais, políticas, históricas e culturais. Logo, quando um determinado grupo reivindica visibilidade social em 
decorrência do apagamento histórico o agrupamento a partir do viés da identidade fica evidente nos fenômenos sociais.

Há diversas pesquisas, sobretudo no campo das Black Digital Humanities, que relacionam as problemáticas de raça $e$ etnia aos estudos sobre tecnologia. Para Gallon (2016), as interações discursivas cotidianas por pessoas negras a partir da apropriação das tecnologias são uma continuação do esforço secular de lutas sociais e políticas empregados por populações negras escravizadas em todo o mundo. Para o autor a Black Digital Humanities gera uma nova epistemologia negra que traz investigações e entendimentos mais profundos sobre a humanidade de maneira geral.

Vemos essa aplicação em trabalhos como os de Freelon et al (2016; 2018) sobre o movimento Black Lives Matter no Twitter sobre movimentos de direitos civis e justiça a partir da análise das hashtag \#Ferguson e \#BlackLivesMatter e a análise do Black Twitter e a relação com mídias jornalísticas ou ainda Noble $e$ Tynes (2016) que tratam de discutir a interseccionalidade na internet a partir de debates em torno de raça, classe, gênero $e$ cultura online. Gray (2012) que analisou a presença de mulheres negras em comunidades online de jogos e Noble (2018) sobre como os algoritmos de grandes plataformas podem ser racistas $e$ machistas, muito em decorrência da hegemonia privilegiada que ocupa os espaços de engenharia das corporações.

Portanto, consideramos de suma importância refletir sobre como grupos não-hegemônicos se apropriam das ferramentas tecnológicas e para além disso, é necessário destacar como denunciam as exclusões resultantes do racismo e do machismo em ambientes relacionados a esse contexto.

\section{Metodologia}

Para compreender o modo como mulheres negras se apropriam das tecnologias em suas práticas de resistência, questão central deste trabalho, analisamos os dados apresentados no relatório resultado do levantamento feito pela PretaLab, bem 
como as entrevistas em vídeo resultantes dos dados $e$ disponibilizadas junto ao relatório na página da organização. Os dados foram analisados tendo por base uma bibliografia que aborda o acesso e uso de tecnologias por pessoas socialmente marginalizadas. Além das informações a respeito de como mulheres negras e indígenas utilizam as tecnologias, foram mencionados nominalmente pelas entrevistadas 15 projetos criados e/ou protagonizados por mulheres negras. Buscamos, dessa forma, compreender quem são essas iniciativas mapeadas, como se apresentam nas redes sociais e como se conectam umas às outras, razão pela qual aplicamos a Análise de Redes Sociais na Internet. As conexões estabelecidas entre essas iniciativas revelam uma das possíveis dimensões de práticas de resistência das mulheres negras por meio das tecnologias.

Já em relação ao método de Análise de Redes Sociais na Internet (Recuero, 2009; Barabási, 2009; Recuero; Bastos \& Zago, 2015; Silva \& Stabile, 2016) é uma abordagem estrutural com o objetivo de compreender aspectos de grupos sociais a partir das relações entre os atores (nós) do grupo. A ARS utiliza dados relacionais como laços, contatos e conexões para destacar os atributos que relacionam os nós da rede. Assim, pretendemos obter por meio deste método dados sobre as estruturas $e$ comunidades das Negras In Tech a partir dos projetos mencionados no levantamento da PretaLab. Deste modo, o procedimento consiste em: 1) pesquisa das páginas de cada projeto na plataforma de mídia social Facebook; 2) busca dos números identificadores (ID) de cada página por meio do site Find My FB ID; 3) coleta dos dados relacionados às redes por meio da ferramenta Netvizz (Rieder, 2013); 4) análise e visualização da rede com a ferramenta Gephi (Bastian et al., 2009).

\section{Cadê elas?}

O Relatório da PretaLab, publicado em fevereiro de 2018 foi elaborado a partir de um levantamento realizado ao longo de 2017 por meio de questionários online. Algumas das questões 
distinguem mulheres negras $e$ indígenas, outros dados são apresentados em conjunto.

No total se contabilizou 570 questionários respondidos, provenientes de 25 estados brasileiros e o Distrito Federal. O relatório disponibiliza uma compilação dos dados levantados. No site da PretaLab também foram disponibilizados 12 excertos de narrativas ${ }^{6}$ sobre as experiências dessas mulheres com as TICs e 10 vídeos curtos, resultados de entrevistas com mulheres negras que atuam com tecnologia. São elas: Ana Carolina Da Hora, Fernanda Lira Monteiro, Gabriela Oliveira, Glória Celeste de Brito, Maria Eloisa, Maria Rita Casagrande, Monique Evelle, Silvana Bahia, Vitória Lourenço e Viviane Rodrigues Gomes. Os vídeos foram dirigidos pela cineasta Yasmin Thayná e alguns trechos dessas entrevistas foram transcritos neste artigo.

Do total de 570 mulheres que responderam o questionário, 547 se autodeclararam negras. Sendo que 58,3\% dessas mulheres negras estão localizadas no sudeste, seja pelo maior acesso à internet nessa região (conforme SIS 2018 o Sudeste é a região com maior índice de acesso à internet, $82,4 \%$ ) ou pelo fenômeno das bolhas-digitais. O Nordeste que aparece em último lugar no acesso à internet segundo a SIS 2018, foi a segunda região com maior número de respostas ao questionário da Preta Lab, resultado da adesão de 60 mulheres na Bahia e 27 em Pernambuco. A parceria com iniciativas como o projeto editorial Desabafo Social de Salvador foi determinante nesse resultado. Entre os Estados, o Rio de Janeiro, sede da organização Olabi que abriga o PretaLab, liderou o número de respostas, 153 no total seguido por São Paulo com 135 respostas.

O levantamento da PretaLab se debruçou sobre o uso $e$ desenvolvimento de tecnologias, duas de três etapas da inclusão digital que seriam: acesso, alfabetização digital e apropriação de tecnologias (Mori, 2011; Rosa, 2013).

A alfabetização digital é elemento essencial para a inclusão digital. De modo que, "as habilidades de uso das TICs são tão ou

${ }^{6}$ Disponível em: https://www.pretalab.com/perfis 
mais importantes do que os indicadores de acesso. Nesta visão, a alfabetização literária é um dos requisitos necessários à "alfabetização digital", e é possível promover ambas conjuntamente" (Mori, 2011:40). Spyer (2017) ao analisar o uso da internet por pessoas de baixa renda no Brasil faz uma observação interessante ao relacionar o aprimoramento da alfabetização como uma consequência inesperada do uso das mídias sociais. De acordo com o autor, a educação é "um elemento de distinção nas mídias sociais" (Spyer, 2017:193), o que leva, especialmente os usuários mais jovens a se sentirem pressionados a escrever corretamente $e$ a "ter vergonha de parentes adultos que não valorizam a educação" (Spyer, 2017:71). Segundo o IBGE (2016), a maior utilização da Internet se relaciona diretamente com os índices de escolarização. Entre a população com 15 anos ou mais de estudo, o que equivale ao Ensino Superior, o percentual de uso da internet é de aproximadamente $90 \%$.

A apropriação das tecnologias é o aspecto sobre o qual esse artigo se debruça. Nas palavras de Silvana Bahia, "a questão das tecnologias é muito mais do que um conhecimento técnico, ela é uma questão política" " . A apropriação das tecnologias é o que possibilita ao indivíduo ser mais que um usuário passivo, mas ser também agente e reinventar seus usos adquirindo autonomia frente às TICs e fazendo uso social das habilidades tecnológicas em seu cotidiano (Mori, 2011; Rosa, 2013).

Na perspectiva de Mori (2011), a inclusão digital no Brasil compartilha das concepções de inclusão social, de modo que adquire uma dimensão cidadã e nesse sentido está no escopo das políticas públicas. A autora atribui à inclusão digital os propósitos de desenvolvimento econômico, solução de problemas sociais $e$ como desenvolvimento multidimensional,

Este conceito prevê o uso das TICs em diferentes aspectos do cotidiano, de maneira integrada ao conjunto dos sistemas que a compõem. Esta visão percebe as tecnologias

${ }^{7}$ Trecho extraído do vídeo Silvana Bahia - Levantamento PretaLab. 
como ferramentas para a garantia de direitos de cidadania em sentido amplo. Enfatiza a necessidade de promover o uso das TICs na melhoria das condições de vida de indivíduos e comunidades desfavorecidas. Uma derivação desta vertente defende a necessidade de políticas públicas que utilizem abordagens participativas, de modo a permitir o uso efetivo das TICs por parte dos indivíduos $e$ comunidades (Mori, 2011: 42).

$\mathrm{O}$ que se entende por tecnologia no relatório PretaLab é o "processo que engloba eletrônica, robótica e inteligência artificial, mas também - e talvez principalmente - a experimentação com fazeres outros que podem ser tradicionais e analógicos" (PretaLab, 2018:7). A gama de funções consideradas no levantamento foi bastante ampla, abarcando profissionais da tecnologia como "engenheiras da computação, tecnólogas, desenvolvedoras de programas computacionais, gestoras de produtos de tecnologias e webdesigners quanto produtoras de conteúdo, ativistas por privacidade, empreendedoras digitais, realizadoras independentes, gambiólogas, cientistas de garagem, aprendizes de Youtube, pesquisadoras, cientistas de dados, entre tantas outras funções nomeadas ou ainda sem nome" (PretaLab, 2018:7). O escopo amplo da definição de tecnologia e das funções exercidas é um aspecto positivo do relatório, pois permitiu às mulheres negras mapeadas pelo levantamento que não atuam formalmente na área, mas fazem incursões no universo da tecnologia, se manifestarem.

A maior parte das mulheres negras envolvidas com tecnologia são jovens entre 17 e 24 anos e somam 35,8\% seguidas pelas mulheres que possuem entre 25 e 29 anos no total de $24,8 \%$. Grupo que corresponde aos chamados nativos digitais, indivíduos que possuem maior desenvoltura com as TICs.

Os nativos digitais, segundo Prensky (2001), possuem a capacidade de realizar múltiplas tarefas, o que representa uma das características principais dessa geração. Ainda segundo esse autor, essa nova geração é formada, 


\begin{abstract}
especialmente, por indivíduos que não se amedrontam diante dos desafios expostos pelas Tecnologias da Informação e da Comunicação (TIC) e experimentam $e$ vivenciam múltiplas possibilidades oferecidas por novos aparatos digitais (Coelho, 2012:90).
\end{abstract}

Acerca do modo como as mulheres negras tiveram contato com a área de tecnologia, a maior parte delas (415 no total) mencionou ter sido por meio da escola, faculdade ou outro centro de ensino formal. É importante salientar que essa questão admitia múltiplas respostas, de modo que era possível apontar concomitantemente outros meios de acesso. Dessa forma, vemos que outras 346 mulheres mencionaram também ter acessado a área de tecnologia por meio da internet e 313 mencionaram ter também adquirido conhecimentos em grupos de apoio que reuniam pessoas negras e/ou indígenas.

Mais do que demonstrar a relevância das instâncias formais de educação no processo de apropriação das tecnologias, esses dados revelam o papel de meios informais para aquisição de conhecimentos na área. Isso talvez possa ser explicado pela insuficiência de políticas públicas de inclusão digital. O Marco Civil da Internet assinado em 2014 prevê a adoção de políticas públicas para universalização do acesso à Internet e à educação digital, no entanto, pouco se avançou nesse sentido desde então. Segundo balanço realizado por Maria Luciano do InternetLab e publicado no site da instituição em abril de 2019, o Brasil segue apresentando profundas desigualdades regionais de acesso, sendo as regiões Norte e Nordeste as que menos acessam internet $e$ o Sudeste a que mais tem acesso, persistem ainda as desigualdades entre áreas rurais e urbanas e entre as classes $\mathrm{A} / \mathrm{B}$ e $\mathrm{D} / \mathrm{E}$. Os usuários das regiões e classes mais afetadas acessam a internet quase exclusivamente pelo smartphone. Acerca da educação digital,

De acordo com dados da TIC Educação 2017, professores avaliam mal as habilidades de seus alunos como avaliar as informações que devem ou não compartilhar na rede 
(43\%), comparar sites identificando as fontes de informação relevantes $(35 \%)$ e interpretar e julgar a confiabilidade das informações disponíveis na rede (27\%). A despeito disso, ações de enfrentamento para problemas ocorridos na internet são priorizadas em detrimento de ações preventivas - apenas $18 \%$ das escolas públicas e $41 \%$ das particulares afirmaram terem realizado palestras, debates ou cursos sobre uso responsável da internet em 2017 (Luciano, 2019:s.p.).

O expressivo número de mulheres negras que adquiriram conhecimentos em tecnologia por outros meios que não a educação formal, evidencia também a cultura da experimentação. Avanços tecnológicos e a multiplicação de tutoriais nas redes favorecem a autonomia do aprendizado em tecnologia (Coelho, 2012). Neuman (2008) destaca que a apropriação tecnológica por grupos socialmente marginalizados é resultado de prática autônoma como as experiências de algumas das entrevistadas pela PretaLab demonstram, a exemplo de Vitória Lourenço que buscou a tecnologia para compreensão da própria gestação, o que a levou ao reconhecimento do fenômeno da violência obstétrica e à prática de doula, Monique Evelle que se insere nas TICs através da criação do Desabafo Social que surge da sua necessidade de discutir publicamente questões raciais e de outras minorias ou mesmo de Day Rosa, cuja experiência tecnológica inicia ainda na infância: "Meu interesse por TI começa cedo com os videogames, $e$ meu sonho era ser desenvolvedora de games. Consegui desenvolver alguns jogos, $e$ as crianças do bairro faziam fila na minha casa para jogar".

Como na questão sobre a forma de acesso aos conhecimentos tecnológicos, a pergunta sobre os usos que as mulheres negras fazem da tecnologia admitiu respostas múltiplas. As respostas com maior adesão foram Comunicação digital (255), Pesquisa de qualquer natureza (188), Empreendedorismo digital (133), Desenvolvimento de software (118) e Sistema de redes, processamento de dados (105). 
A despeito da centralidade da comunicação nas TICs, uso prioritário da maior parte da população, para grupos historicamente marginalizados dos veículos de mídia, as tecnologias e a internet em especial abriram um campo vasto de possibilidades para discussão de suas demandas, troca $e$ compartilhamento de informações - sejam elas para uso com fins sociais como aquele feito pelo Coletivo Papo Reto do Complexo do Alemão (cuja idealizadora é Lana Souza, uma jovem negra) que mantém um canal para recebimento e divulgação de vídeos de abordagens policiais violentas no Rio de Janeiro ou sejam elas para facilitar a vida cotidiana como os grupos de linhas de ônibus no WhatsApp onde passageiros, motoristas e cobradores compartilham informações sobre lotação e atraso nas linhas ${ }^{8}-, e$ ainda a constituição de um espaço de visibilidade $e$ reconhecimento, como exemplificam os relatos de Maria Rita Casagrande e Gabi Oliveira entrevistadas pela PretaLab.

Voz e possibilidade, isso são coisas que a tecnologia me trouxe (Maria Rita Casagrande).

[...] eu gosto sempre de incentivar as pessoas a entrarem no YouTube. Principalmente as meninas negras que é o público que eu tenho mais contato porque eu acho que a gente tem muita coisa para falar e a gente precisa falar sobre tudo. Eu quero ter uma youtuber que fale sobre culinária, quero ter uma menina negra falando sobre viagem, um menino negro ou uma menina negra falando sobre game. Para eu chegar até as outras pessoas eu preciso da tecnologia. Então para mim hoje tecnologia é conexão. Até eu ter espaço de voz, muitas outras mulheres lutaram antes de mim (Gabi Oliveira).

\footnotetext{
8 Conforme matéria desenvolvida pela Revista Época e informações disponibilizadas na página do Coletivo Papo Reto no Facebook. https://epocanegocios.globo.com/Brasil/noticia/2019/06/passageiros-de-onibusdo-rio-tem-grupo-de-whatsapp-que-ja-rendeu-festas-romance-e-emprego.html $e$ https://www.facebook.com/ColetivoPapoReto/.
} 
Perguntadas sobre o que as atraiu para a tecnologia, $29,1 \%$ das mulheres negras e indígenas que responderam ao questionário mencionaram o potencial de inovação, $14,6 \%$ as possibilidades de transformação social e 13,9\% o alcance. Apenas 9,6\% dessas mulheres mencionaram a carreira como motivo para buscarem a área de tecnologia ${ }^{9}$. Nesses números três dados se destacam, a baixa adesão à carreira em tecnologia, o uso social dessas ferramentas e o potencial de inovação.

Barreiras materiais e simbólicas geram obstáculos para que mais mulheres negras invistam profissionalmente nessas áreas. Araújo e Rego (2018), analisam essa situação a partir da seguinte perspectiva,

\begin{abstract}
Todas elas, negras ou brancas, são "empurradas" para corresponder a certos papéis de gênero, que contemplam universos distantes do da Ciência e Tecnologia. A responsabilidade social face a questões como esta deve ser largamente partilhada: entre as instituições, o governo, mas também entre os progenitores que educam seus filhos $e$ filhas de maneira a encaixá-los em "gavetas" de estereótipo. [...] ouvir uma mulher negra, bem-sucedida, a falar de como é possível (e importante) chegar ao ativismo digital ou ao empreendedorismo, permite que as meninas mais novas, que se veem refletidas naquela figura, também negra e do sexo feminino, criem uma referência positiva a respeito delas próprias $e$ a respeito da possibilidade de se tornarem profissionais de Ciência e Tecnologia (Araújo; Rego, 2018).
\end{abstract}

Os dados do levantamento demonstraram que as mulheres negras que responderam ao formulário e cederam entrevistas em vídeo reconhecem nas tecnologias seu potencial para aquisição $e$ construção de conhecimento, para além de uma finalidade econômica.

\footnotetext{
${ }^{9}$ Num levantamento posterior a PretaLab - em parceria com a ThoughtWorks (consultoria global de software) - explorou a percepção sobre a diversidade em carreiras tecnológicas.
} 
Para começar a entender a tecnologia num aspecto que não era só mercado. A gente não é encorajada a fazer tecnologia como uma forma de aprender, como uma forma de inventar, como uma forma de resistir. A importância de você entender programação não é só você desenvolver tecnologia ou você criar uma proximidade com a máquina. Às vezes é você criar uma proximidade com aquilo que você gostaria de criar e às vezes não teve oportunidade (Fernanda Monteiro Lira).

Essas mulheres se apropriam e buscam através da tecnologia caminhos para solução de problemas sociais.

\section{Rede Negras in Tech}

As redes sociais existem desde os primórdios da sociedade, a transposição dessa prática para o ambiente digital revela um reforço na construção de capital social e difusão, essas ocorrem como resultados das interações, conexões, publicações $e$ percepções. Dessa forma a proposta de Análise de Redes Sociais aqui empregada tem como objetivo mapear as interações $e$ principais referências na circulação de informações, além da própria construção de capital social. Assim podemos observar como as iniciativas se apropriam da plataforma do Facebook enquanto representação de seus projetos para propagar conteúdo, convocar interessadas e, sobretudo analisando a rede estabelecida, a construir relações a partir de mesmo propósito.

A rede Negras In Tech teve como nós semente as páginas no Facebook dos 15 projetos mencionados no levantamento da PretaLab, são eles OxenTI Menina, Criola, Blogueira Negras, Pretas Hackers, Desabafo Social, GatoMidia, Minas Programa, DataLabe, BlackRocks Startup, MariaLab, Preta, Nerd e Burning Hell, Info Preta, Instituto Mídia Étnica, Coletivo Nuvem Negra e Olabi / PretaLab. Dessa base foi gerada uma rede de 376 nós e 
1.068 arestas com grau médio ${ }^{10}$ de 2,84 , diâmetro ${ }^{11}$ da rede de 13 , densidade ${ }^{12}$ de 0,008 e modularidade $0,645^{13}$ com 9 clusters.

De todos esses nós resultantes da rede os que se destacam a partir da métrica do grau é o projeto minasprogramam com 147, dos quais 23 são grau de entrada e 124 de saída. Na sequência vem a página Preta, Nerd e Burning Hell com 81, sendo 10 de grau de entrada e 71 de saída. Em terceiro lugar o projeto Olabi com 71, dos quais 12 são grau de entrada e 59 de saída. O projeto GatoMÍDIA fica em quarto lugar com 54, desses 15 são grau de entrada e 39 de saída e em quinto lugar de destaque o Blogueiras Negras com 46, sendo 16 grau de entrada e 30 de saída. Isso significa que essas páginas são referências e nós que conectam vários atores na rede, como melhor demonstrado na figura 1 abaixo.

\footnotetext{
${ }^{10}$ A métrica permite a identificação do nó com maior número de conexões.

${ }^{11}$ A métrica mede a maior distância entre nós da rede.

${ }^{12}$ A métrica informa a quantidade de conexões em relação ao número total de conexões possíveis no grafo, aqui temos um grafo pouco conectado.

${ }^{13}$ A métrica permite a identificação dos clusters.
} 


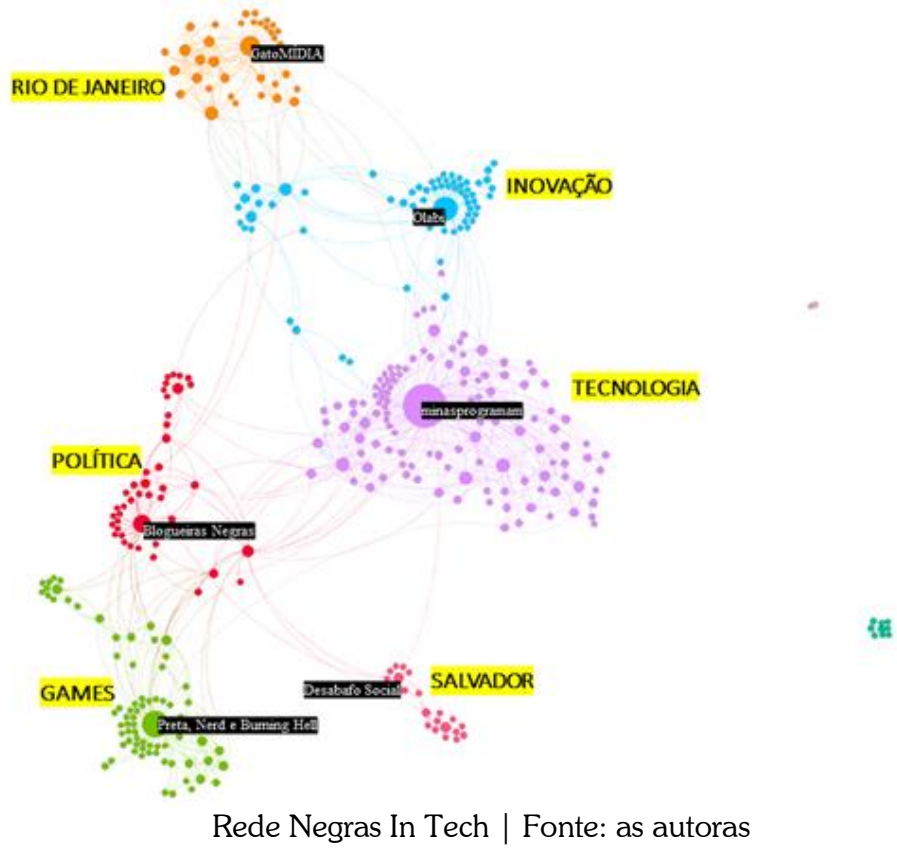

Sobre a métrica de modularidade, obtivemos nove comunidades com particularidades em cada uma delas. Descreveremos abaixo com mais detalhes:

Cluster lilás - Tecnologia: essa comunidade tem como destaque o projeto minas programam e sua maioria de nós tratam da temática de mulheres nas tecnologias, como MariaLab, Programaria, Girls in Tech - Brazil, MNT - Mulheres na Tecnologia, Mulheres na Computação, National Center for Women \& Information Technology (NCWIT), entre outras referências. Observamos também neste cluster páginas relacionadas a temática feminina e feminista, destacam-se Blogueiras Feministas, Capitolina, MAMU - Mapa de Coletivos de Mulheres, Thing Olga, Nós, mulheres da periferia e Lugar de Mulher.

Cluster verde - Games: nesta comunidade o projeto Preta, Nerd e Burning Hell se destaca entre os nós e é responsável por se conectar a diversos outros nós da temática do universo geek e nerd, como Women Write About Comics, Negra e Nerd, Black 
Nerd Comedy, Gamer, você é Machista, Black SuperHeroes, O Lado Negro da Força, entre outras. Também é possível observar neste cluster atores que abordam a questão da estética negra, por exemplo o filme KBELA, Faça amor, não faça chapinha e Elogie uma Irmã Negra.

Cluster azul - Inovação: nesta comunidade o projeto Olabi se destaca com maior relevância dentre os nós e se conecta com outros atores relacionados à pesquisa e inovação, como Oficina de Escrita para Mulheres, Departamento de Arquitetura e Urbanismo PUC-Rio, GNOva - Laboratório de Inovação em Governo, Encontro Internacional de Cultura Livre e Inovação Cidadã, ELAS nas Exatas, entre outras. Neste cluster é possivel observar ainda um aglomerado de nós que trazem como temáticas, territórios periféricos das cidades, como o Observatório de Favelas, Galpão Bela Maré, DataLabe, Periferia em Movimento e Énois.

Cluster vermelho - Política: o projeto Blogueiras Negras é o nó em destaque nessa comunidade e se conecta com atores que abordam temáticas políticas e aproximações, como MeRepresenta e Virada Política. Destacam-se ainda organizações de universidades ou relacionadas à academia, como Coletivo Feminista de Dança - FEMME UFPE, Facultad de Derecho - UP, Universidade Estadual do Norte Fluminense Darcy Ribeiro, FEUSP - Faculdade de Educação da USP e o coletivo Preta \& Acadêmica. Observamos também organizações da iniciativa civil como o Geledés Instituto da Mulher Negra, Artigo 19, Oxfam Brasil, ELAS Fundo de Investimento Social e Agência Patrícia Galvão.

Cluster laranja - Rio de Janeiro: nesta comunidade o projeto GatoMíDIA é o nó em destaque o que faz deste cluster estar conectado em diversos outros projetos situados na cidade do Rio de Janeiro, como Comida de Favela, Redes da Maré - Somos Todos Maré, Foto Favela, Redação Jornal Voz Da Comunidade, Favelados pelo Mundo, Todos Pelo Alemão, Territórios Culturais RJ / Favela Criativa, Cdd Acontece, entre outras. Também observamos nesta comunidade a presença de organizaçóes como Fundação Via Varejo e Fundação Heinrich Boll Brasil. 
Cluster vinho - Salvador: nesta comunidade observamos como destaque três projetos originados na cidade de Salvador, o Desabafo Social, Portal Correio Nagô e o Instituto Mídia Étnica. Esse cluster apresenta uma extensão reduzida quando comparado aos demais, ao todo tem 21 nós.

Por fim, as últimas três comunidades somam juntas 12 nós e são compostas por Oxenti Menina, Latinidades Afrolatinas, BlackRocks Startup, InfoPreta, Caió Cosméticos Naturais, Revista Sustentabilidade, Martin Luther King Jr., Livraria Cultura, Causos do Metrô de SP, Reciclartè, Melhores Momentos da Vida - Pelo Mundo e Atitude Sustentável.

As páginas relacionadas à comunidade de tecnologia formam a grande comunidade e se relaciona com intensidade com as demais temáticas. A responsável por parte dessa conexão é a página do projeto Minas Programam que se conecta a 124 outras páginas e recebe 23 conexões. As temáticas que se sobressaem na rede demonstram relação coerente com o ecossistema de modo geral, tais como tecnologia, inovação, games e política. É interessante observar os marcadores territoriais das cidades do Rio de Janeiro e Salvador, o que demonstra certa valorização dos projetos baseados em uma determinada regionalidade.

Por meio das conexões é possível notar um reforço $e$ valorização de identidade da mulher negra na medida em que páginas como Elogie Uma Irmã Negra, Faça amor, não faça chapinha e Nós, mulheres da periferia aparecem entre as referências na rede. Há ainda diálogo com a academia, setor público e iniciativa privada ao observarmos a quantidade de páginas relacionadas à universidades, órgãos públicos e fundações de empresas - essas provavelmente por conta dos editais $e$ financiamentos a projetos - aparecem em clusters específicos.

\section{Considerações finais}

Tendo em vista as precárias condições socioeconômicas que grande parte das mulheres negras enfrentam, como vários indicadores, alguns deles apresentados neste texto, revelam $e$ 
considerando que as áreas tecnológicas não são economicamente tão acessíveis, e ainda, a ausência ou insuficiência de políticas públicas para as mulheres na tecnologia, os dados apresentados pela PretaLab no relatório são reveladores da conduta de resistência adotada por essas mulheres.

As tecnologias são para os grupos sociais marginalizados, conforme Neuman (2008), de "origem exógena". Tais grupos não são os criadores dessas tecnologias, elas lhes são impostas no contexto do mundo globalizado e de capitalização da informação. A autora atribui às TICs um dos mecanismos mais bem sucedidos da globalização devido a sua difusão, mas também um dos mais permeáveis, pois pode ser utilizada pelos grupos subalternos como ferramenta de resistência e negociação dentro desse contexto, mesmo considerando seu uso para o exercício do controle social.

É nesse sentido que Conley (2017) ao analisar o uso de hashtags por feministas negras norte-americanas, defende que as mulheres negras subverteram o uso original dessa ferramenta ao utilizá-la para mediar conexões no tempo e no espaço, estabelecendo laços com experiências de outras mulheres negras, confrontando as estruturas dominantes que as marginalizam num processo de criação e recriação de suas próprias identidades e na produção de formas não padronizadas de conhecimento.

As TICs oportunizam às mulheres negras "a possibilidade de reforçar identidades coletivas, de explorar novas identidades, de superar barreiras sociais e culturais, de dar novos sentidos ao exercício da cidadania através da visibilidade de seus discursos" (Santos, 2018:118).

A Rede Negras In Tech - desenvolvida por meio da Análise de Redes Sociais no intuito de compreender as dinâmicas dos projetos mencionados no PretaLab Report - apresentou um desenho de relações que reflete a pluralidade das temáticas que permeiam as principais discussões sobre/de mulheres negras na sociedade contemporânea. Observamos, portanto, que as mulheres negras brasileiras, a partir de suas representações na rede, se apropriam das ferramentas online para formar comunidades, propagar os propósitos coletivos relacionados ao 
aprendizado e apropriação da tecnologia, disseminar informação relevante, bem como para se conectar e estabelecer relações em torno de outros tópicos da vida social, como demonstrado na comunidade de games, política e demarcações territoriais e assim desenvolvem seus espaços de visibilidade e resistência. A potencialização das vozes de mulheres negras se faz presente na interação discursiva desses projetos que, em certa medida, representam no fazer cotidiano outras mulheres negras que visam adquirir ou repassar conhecimento sobre a tecnologia, vivências $e$ estratégias para resistir.

Dessa forma, em resposta à pergunta norteadora deste estudo, ou seja, "De que forma as mulheres negras brasileiras têm se apropriado de ferramentas tecnológicas como estratégias de resistência?", temos que tais mulheres se apropriam das ferramentas com $\mathrm{o}$ intuito de propor soluções às brechas tecnológicas, sobretudo a brecha de conhecimento ao buscar meios formais e não-formais de obtenção de conhecimento para criação e manipulação de tecnologias, de modo a obter autonomia frente às TICs e fazer uso social das habilidades tecnológicas adquiridas na promoção de inovação $e$ transformação social. Assim, observamos práticas genuínas e constantes de resistência e negociação diante dos processos de globalização e avanço tecnológico.

A formação de redes a partir de demarcador de identidade de raça e gênero possibilitam a circulação de outras visões de mundo que não as hegemônicas, a interação discursiva $e$ o desenvolvimento de comunidades. Essas características fortalecem o entendimento do que é pertencer e assim essas mulheres negras reunidas elaboram estratégias para fugir dos estigmas e da marginalização decorrentes das disparidades sociais.

O levantamento da PretaLab proporcionou às mulheres negras que participaram da pesquisa atribuírem usos e sentidos para além dos requisitos técnicos, vemos então menções a experimentação criativa como webdesign, empreendedoras digitais, ativistas, gambiológas, produtoras de conteúdo entre outros. Além dos meios formais como modo de adquirir 
conhecimento, estas mulheres mencionam a própria internet como fonte de conhecimento e grupos de apoio, reforçando o caráter essencial da criação e manutenção de redes.

\section{Referências bibliográficas}

ARAÚJO; REGO, 2018. É urgente incluir mais mulheres (negras) no universo da tecnologia. Geledés: Instituto da Mulher Negra (site), set.2018 [ttps://www.geledes.org.br/e-urgente-incluir-mais-mulheresnegras-no-universo-da-tecnologia/. Acesso em 16 set. 2019].

BARABÁSI, Albert-László. Linked - a nova ciência dos networks. São Paulo, Leopardo, 2009.

BASTIAN, Mathieu et al. Gephi: an open source software for exploring and manipulating networks. Icwsm, v. 8, p. 361-362, 2009 [https://gephi.org/publications/gephi-bastian-feb09.pdf. Acesso em 10 set. 2019].

BRAGA, Renê Morais da Costa. A indústria das fake news e o discurso de ódio. In: PEREIRA, Rodolfo Viana (org.). Direitos políticos, liberdade de expressão e discurso de ódio. Belo Horizonte, Instituto para o Desenvolvimento Democrático, 2018.

CANCLINI, Néstor Garcia. Diferentes, desiguais, desconectados. Rio de Janeiro, Ed.UFRJ, 2015.

CODING RIGHTS; INTERNETLAB. Violências contra mulher na internet: diagnóstico, soluçôes e desafios. Contribuição conjunta do Brasil para a relatora especial da ONU sobre violência contra a mulher. São Paulo, 2017 [https://www.internetlab.org.br/wpcontent/uploads/2017/11/Relatorio_ViolenciaGenero_ONU.pdf. Acesso em 15 de set. 2019]

COELHO, Patrícia Margarida Farias. Os nativos digitais e as novas competências tecnológicas. Revista Texto Livre, ano2, vol.5, $\mathrm{n}^{\circ} 2$ [http://periodicos.letras.ufmg.br/index.php/textolivre. Acesso em 25 jun.2019].

COLLADO, Cecilia Castaño. La segunda brecha digital y las mujeres. Telos: Cuadernos de Comunicación e Innovación (digital), nº75, abrjun.

2008 
[https://telos.fundaciontelefonica.com/archivo/numero075/la-segundabrecha-digital-y-las-mujeres/. Acesso 16 set.2019].

CONLEY, Tara L. Decoding Black Feminist Hashtags as Becoming. Journal of Black Studies and Research, Volume 47, 2017 [https://www.tandfonline.com/doi/abs/10.1080/00064246.2017.1330

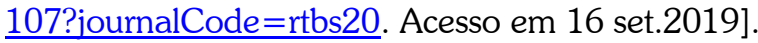

COSTA, Maria Conceição; LIMA, Betina Stefanello Lima. Gênero, ciências e tecnologias: caminhos percorridos e novos desafios. Cadernos pagu (48), Campinas, 2016 [https://www.scielo.br/scielo.php?script=sci_arttext\&pid=S0104$83332016000300304 \& \operatorname{lng}=e n \& n r m=i s o \& t \operatorname{lng}=e n$. Acesso em 05 de ago de 2020].

DANIELS, Jessie. Race and racism in Internet studies: A review and critique. New Media \& Society, v. 15, n. 5, 2013, pp.695-719 [https://journals.sagepub.com/doi/10.1177/1461444812462849. Acesso em 29 de ago. 2019].

FREELON, Deen. The Measure of a Movement: Quantifying Black Lives Matter's Social Media Power. Upenn. edu, 2016.

; MCILWAIN, Charlton; CLARK, Meredith. Beyond the hashtags: \#Ferguson, \#Blacklivesmatter, and the online struggle for offline justice. Washington-DC, CMSI - American University, 2016.

et al. How Black Twitter and other social media communities interact with mainstream news. Knight Foundation, 2018.

GALLON, Kim. Making a case for the Black digital humanities. In: GOLD, Matthew; KLEIN, Lauren. Debates in the Digital Humanities, 2016, pp. $42-49$ [https://journals.sagepub.com/doi/10.1177/1461444812462849]. Acesso em 10 de set. 2019.

GOMES, Nilma Lino et al. Alguns termos e conceitos presentes no debate sobre relações raciais no Brasil: uma breve discussão. Educação anti-racista: caminhos abertos pela Lei Federal, v. 10639, $\mathrm{n}$. 03 , 2005 [http://pronacampo.mec.gov.br/images/pdf/bib_volume2_educacao_a nti_racista_caminhos_abertos_pela_lei_federal_10639_2003.pdf Acesso em 28 de ago. 2019] 
GRAY, Kishonna L. Intersecting oppressions and online communities: Examining the experiences of women of color in Xbox Live. Information, Communication \& Society, v. 15, n. 3, 2012, pp.411428

[https://www.tandfonline.com/doi/abs/10.1080/1369118x.2011.6424 01 . Acesso em 14 de ago. 2019]

HARDING, Sandra. Ciência e tecnologia no mundo pós-colonial e multicultural: Questões de gênero. Labrys: estudos feministas. número 3 , janeiro/ julho 2003 [https://www.labrys.net.br/labrys3/web/bras/sandra1.htm. Acesso em 06 de agosto 2020].

HEARN, Jeff; HUSU, Liisa. Understanding Gender: Some Implications for Science and Technology. Interdisciplinary Science Reviews, vol. 36, 2011.

HINE, C. Ethnography for the internet: embedded, embodied and everyday. Huntingdon, GBR, Bloomsbury Publishing, 2015.

INTERNETLAB; REDE CONHECIMENTO SOCIAL. Domésticas conectadas: acessos e usos de internet entre trabalhadoras domésticas em São Paulo. São Paulo, 2018 [https://www.internetlab.org.br/wpcontent/uploads/2018/07/domesticas-conectadas_pdf]. Acesso em 15 de set. 2019]

LEMOS, André. Cibercultura - Tecnologia e vida social na cultura contemporânea. Porto Alegre, Sulina, 2015.

LUCIANO, Maria. 5 anos depois: um balanço das políticas públicas de internet no Brasil. 2019 [http://www.internetlab.org.br/pt/especial/5-anos-depois-um-balancodas-politicas-publicas-de-internet-no-brasil/. Acesso em 16 set.2019].

MORI, Cristina Kiomi. Políticas públicas para inclusão digital no Brasil: aspectos institucionais e efetividade em iniciativas federais de disseminação de telecentros no período 2000-2010. Tese de Doutorado em Serviço Social, Instituto de Ciências Humanas, Universidade de Brasília, Brasília, 2011.

MUNANGA, Kabengele. Rediscutindo a mestiçagem no Brasil identidade nacional versus identidade negra. Petrópolis, Vozes, 1999. 
. Kabengele. Negritude - Usos e Sentidos. $3^{\mathrm{a}}$ ed. $1^{\mathrm{a}}$ reimp. Belo Horizonte: Autêntica, 2012.

NATANSOHN, Graciela. Por uma agenda feminista para internet $e$ as comunicações digitais. In: PELUCIO, Larissa; PAIT, Heloísa e SABATINE, Thiago (org.). No Emaranhado da Rede - gênero, sexualidade e mídia, desafios teóricos e metodológicos do presente. São Paulo: Annablume, 2015.

NEUMAN de SEGAN, María Isabel. La apropiación tecnológica como práctica de resistencia y negociación en la globalización. En IX Congreso Latinoamericano de Investigadores de la Comunicación, AMIC, México [https://www.researchgate.net/profile/Maria_Neuman/publication/2966 69418 La_apropiacion tecnologica_como_practica_de resistencia y negociacion en la globalizacion/links/56d77d8008aebe4638af1f1e/ La-apropiacion-tecnologica-como-practica-de-resistencia-ynegociacion-en-la-globalizacion.pdf. Acesso em 16 set. 2019].

NOBLE, Safiya Umoja; TYNES, Brendesha M. The intersectional internet: Race, sex, class, and culture online. New York, Peter Lang International Academic Publishers, 2016.

- Algorithms of Oppression: How Search Engines Reinforce Racism. New York, NYU Press, 2018.

PEREIRA, Marcus Abílio; SANTOS, Pedro. Violência coletiva e o Facebook: Os protestos de junho de 2013 no Brasil. In: FILGUEIRAS, Fernando; MENDONÇA, Ricardo Fabrino; PEREIRA, Marcus Abílio (org.). Democracia digital: Publicidade, instituiçóes e confronto político. Belo Horizonte: UFMG, 2016.

PICCININ, Fabiana; DE CASTRO, Henrique Carlos de O.; CASTILLO, Sofía Vizcarra. Fake News nas eleições: notas sobre a crise de confiança e a cultura política brasileira. Anais de Artigos do Seminário Internacional de Pesquisas em Midiatização e Processos Sociais, v. 1, n. 3 , ago. 2019. [http://www.midiaticom.org/anais/index.php/seminariointernacional/ar ticle/view/269.Acesso em: 18 set. 2019].

PRETALAB REPORT [https://www.pretalab.com/. Acesso em 18 set. 2019]. 
RECUERO, Raquel. Redes Sociais na Internet. Porto Alegre, Sulina, 2009.

. BASTOS, Marco; ZAGO, Gabriela. Análise de redes para mídia social. Porto Alegre, Sulina, 2015.

RIEDER, Bernhard. Studying Facebook via Data Extraction: The Netvizz Application

[http://thepoliticsofsystems.net/permafiles/rieder_websci.pdf]. Acesso em 24 de set. 2019.

ROSA, Fernanda Ribeiro. Inclusão digital como política pública. jun. 2013 Revista Internacional de Direitos Humanos. [https://sur.conectas.org/inclusao-digital-como-politica-publica/.Acesso em 05 de agosto 2020].

SANTOS, Céres Marisa Silva dos. La apropriación de las TIC por mujeres brasileñas. In: FARRERA, Abrahan Mena; PABLOS, Esperanza Tuñón (cord.). Género y TIC. San Cristóbal de Las Casas, Chiapas, México, Ed. Ecosur, 2018

SILVA, Tarcízio; STABILE, Max (org.) Monitoramento e pesquisa em mídias sociais: metodologias, aplicações e inovações. São Paulo, Uva Limão, 2016.

SILVEIRA, SA. Ensaio: Convergência digital, diversidade cultural e esfera pública. In PRETTO, NL.; SILVEIRA, SA. (org.). Além das redes de colaboração: internet, diversidade cultural e tecnologias do poder. [online]. Salvador, EDUFBA, 2008.

SPYER, Juliano. Social Media in Emergent Brazil How the Internet Affects Social Change. UCL Press - University College London, 2017.

STEIN, Marluci; NODARI, Cristine H.; SALVAGNI, Julice. Disseminação do ódio nas mídias sociais: análise da atuação do social media. Revista Interações, Campo Grande, MS, v. 19, n. 1, jan./mar. 2018, pp.43-59 [https://www.scielo.br/pdf/inter/v19n1/1518-7012-inter-1901-0043.pdf. Acesso em 20 set. 2020].

WAJCMAN, Judy. Reflections on Gender and Technology Studies: In What State is the Art? Social Studies of Science, vol. 30, n. 3 Jun., 2000, pp.447-464 [https://www.jstor.org/stable/285810?seq=1]. Acesso em 20 set. 2020]. 